jects outside their ken, as witness Kaler's strange views on barred galaxies or on synchroton radiation. And Mann, for all his wisdom, delivers himself of the following insight: "the supernova phenomenon... is an event with far more violence than humans can produce, but unlike much of our violence it is not mindless". Something inside one boggles. A learned rabbi once told me that no human construct should ever be expected to be perfect, and that only the Almighty can achieve perfection. He was probably right.

F. D. Kahn is in the Department of Physics and Astronomy, University of Manchester, Manchester M13 9PL, UK.

\section{Tomato-watching in a dark corner}

\section{Readings on Color: Volume 1- The Philosophy of Color; Volume 2- The Science of Color}

edited by Alex Byrne and David R. Hilbert

MIT Press: 1997. Pp. 317/465. \$50, £42.50

( $h b k$ ), $\$ 30$, 225.50 (pbk) each

\section{Michael Morgan}

Are tomatoes red in the dark? If your interest in this question was extinguished by latenight discussions with your undergraduate friends, read this review no further. Otherwise, open Volume 1 of this book and meet "Mary the super-scientist" who doesn't know what it's like to see red; the "Invert" who sees tomatoes as blue; and - for all I know, since I skipped a few pages - Superman, with his useful ability to see colours under short-wavelength illumination.

Both volumes are aimed, it seems, primarily at philosophers. The editors are philosophers at the Massachusetts Institute of Technology and the University of Illinois.

I learned from a recent radio broadcast by the UK geneticist Steve Jones that London's Albert Hall, home of the Promenade Concerts, was originally intended as part of the 'Albertopolis project' that would unite the sciences and the arts, following the successful Exhibition of 1851. Alas, all that resulted from Prince Albert's grand scheme was an exhibition of Bulgarian wine in the Albert Hall.

When asked by Jones to account for the failure of the Prince Consort's project to unite the sciences and the arts, the present secretary to the commissioners for the 1851 Exhibition, Patrick Middleton, observed, interestingly, that he blamed the philosophers. Philosophers, he said, are supposed to keep knowledge from fragmenting. Instead, they have retreated into a dark little corner of their own, in which philosophers are experts on philosophy. No more contemplation of the starry heavens above and the moral law within, thank you very much.
Alex Byrne and David R. Hilbert deserve credit for joining the 'neurophilosophers' who are trying to bring philosophers back to science. They clearly believe that philosophers who want to study colour should know some colour science.

Volume 1 shows how desperately this reform is needed. Let us join the philosophers in considering the unilluminated tomato. Is the tomato a fruit or a vegetable? No, sorry, that's a different problem - I mean is it red in the dark? I take it that no colour scientist would disagree with the following.

Of course, we do not see the tomato as red in the dark, and will not do so until transgenics offers us a combination of the tomato and the deep-sea fish. But the tomato in the dark has a surface reflectance spectrum that causes it, in daylight, to look red to us. The light that reaches our eye is a mathematical product of the surface reflectance spectrum of the tomato and the spectrum of the illuminant — say, northern daylight. The tomato continues to look red when illuminated by sunlight bouncing off green leaves. But this colour constancy has its limits. The tomato does not look red under sodium streetlights, and it most emphatically does not look red in the dark.

Whether one says tomatoes are red in themselves or not would seem to most scientists to be a fairly uninteresting question for the attention oflexicographers. But if you are a certain kind of philosopher, you take sides on the question and fight your corner.

You claim, like J. J. C. Smart, that colours are properties of objects, and you are a physicalist; or you say they are properties of objects that cause colours to be seen, and you are a dispositionalist; or you adhere to eliminativism and say that colours are illusions. Or, if you are a sensible sort of chap - and they nearly all are chaps you say there is merit in all these positions. The economic advantages of a system in which everyone is paid to take in everybody else's washing are thereby convincingly demonstrated.

Most of the articles reprinted in The Philosophy of Color rehash the physicalist versus dispositionalist versus eliminativist positions until one groans with boredom. Having once put the book down, I had great difficulty in picking it up again. Why do so many philosophers prefer thought-experiments to real ones?

For example, we read in one chapter: "Surely, people can see things as red without even having the concept of a tomato or a [British] phone booth". But could one in fact see red without any concept of red objects: if one had never associated warmth with the red Sun seen through closed eyelids? Probably, but I see no "surely" about it.

To be fair, some chapters, and particularly the one by the editors themselves, do deal with recent discoveries about the properties of nat- urally occurring surface reflectance spectra. And Justin Broakes contributes an interesting chapter, describing the colours that emerge from flickering achromatic stimuli in Benham's top, and the doomed Butterworth encoder which tried to use this as a basis for colour television.

But elsewhere it is all Mary the superscientist and her relatives. Why don't Mary's friends consider instead the far more interesting cases of real people with defective colour vision in one eye, who are described nicely in Volume 2?

Also, to be fair, scientists play some part in causing confusion. Newton's statement that the "Rays are not coloured" is well known. Galileo is quoted on page 81: "Hence I think that these tastes, odours, colours etc. are nothing else but mere names." I recall a public lecture by an eminent colour scientist entitled "Colour: The Great Illusion". If colour is an illusion, then so too is the movement seen in the cinema or television. But it is pointless to argue about an issue that is merely terminological.

Let us return to the science. The chapters in Volume 2 are mostly reprinted from scientific journals. We learn from the introduction that the selections were chosen "with an eye to their philosophical relevance". This rang alarm bells for me. All advances in colour science are of philosophical relevance if philosophy is to be understood in the generous spirit of the chairman of the commissioners for the 1851 Exhibition. It is a copout to suggest to philosophers that they can pick the plums out of the literature without being troubled by the details.

Many solid scientific papers are here, to be sure, but it is scarcely believable that the most recent paper on the neural coding of colour is from 1977! The term "cardinal axis" figures neither in the helpful glossary nor in the index. The key question of how the achromatic and chromatic signals are disentangled from the univariant parvocellular pathway is nowhere to be found: the reader has to make do with a paper from 1982 .

To call this collection heteroclitic would be to exaggerate its cohesiveness. The editors do not seem to have made up their minds whether to present a volume of classic papers or one of recent advances. Physiology, as I have indicated, is particularly badly served. On the other hand, molecular genetics is well represented by a Scientific American article by Jeremy Nathans, and there is welcome attention paid to the ecology and evolution of colour vision. The chapters on the physics and chemistry of surfaces will be useful to many colour scientists.

Interestingly, what is completely lacking is anything serious on the aesthetics of colour. Could not painters claim to be the true experts on colour science? The Albert Hall lies only a few minutes' walk from London's Imperial College of Science, Technology and Medicine, 
but this is still too far, it seems, for modern philosophers.

Michael Morgan is at the Institute of

Ophthalmology, University College London,

11-43 Bath Street, London EC1V 9EL, UK.

\section{Related book}

Do visual science and anthropological linguistics have anything to say to each other? Does the make-up of our colour-vision system constrain our linguistic expression of colour categories? Does the way we use colour language suggest anything about the biological organization of colour vision? These are the questions addressed in Color Categories in Thought and Language edited by C. L. Hardin and Luisa Maffi (Cambridge University Press, £55, \$74.95 (hbk), £19.95, \$27.95 (pbk)), which unfortunately arrived too late for inclusion in Michael Morgan's review above. The book arose from a 1992 conference which brought together visual scientists, psychologists, linguists and anthropologists to examine claims that commonalities of basic colour term use extend across languages and cultures and probably express universal features of perception and cognition.

\section{Mind over chatter}

\section{The Symbolic Species: The Co- Evolution of Language and the Brain} by Terrence Deacon

Norton/Allen Lane: 1997. Pp. 496. \$27.50,

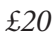

\section{David Poeppel}

One of the troubling things about studying language is that almost everyone is willing to contribute an opinion on how language works, including scientists from other fields who should know better. This is not typically true when one studies, say, the kidney or motor control. Language is viewed as an area that licenses unconstrained speculation. Despite all lay intuitions, however, the scientific study of language requires technical expertise.

Terrence Deacon's The Symbolic Species exemplifies how an ambitious book about the coevolution of language and the brain fails because one half of the question (how language works) is treated in an outdated and superficial way. The author aims for a theory of language but develops a theory of everything, ranging from word meaning to empathy to consciousness. I, for one, am invariably suspicious of theories of everything.

In modern cognitive science, neuroscience and psychology, two strongly opposed positions about language dominate the agenda. One position is that acquiring, knowing and using language all reflect the existence of a specialized cognitive system or 'language faculty'. In this view, language con- stitutes an autonomous mental domain, independent of other cognitive abilities such as face recognition or inductive reasoning. This framework was most forcefully developed by Noam Chomsky and has recently received a popular exposition in Steven Pinker's The Language Instinct (Morrow/ Allen Lane, 1994). An important assumption of the domain-specific framework is that the ability to learn language is innately specified. In today's climate in cognitive science and neuroscience, Chomsky, Pinker and other researchers with nativist inclinations are often considered the 'bad guys'.

The 'good guys' (who I believe are wrong) argue that it is unnecessary to posit languagespecific innate machinery. Instead, general learning and developmental mechanisms designed to constrain learners provide sufficient explanatory infrastructure to account for the phenomena of language. A recent empiricist manifesto of this sort is J. Elman et al's Rethinking Innateness (MIT Press, 1996).

The position endorsed by Deacon is clear: "No innate rules, no innate general principles, no innate symbolic categories can be built in by evolution". Perhaps this shows a poverty of the imagination. Deacon arrives at this pronouncement from a comparative and evolutionary perspective. What does this mean? First, that he compares animals and humans. Second, that he wants to explain the coevolution of language and the brain in a way that maintains the continuity of brain evolution in the face of the discontinuity in behaviour: humans have language, animals do not. He is particularly impressed with the communicative abilities of Kanzi, the chimpanzee trained by Sue Savage-Rumbaugh, who offers a "devastating challenge to the nativist, Chomskyan perspective". Precisely what that challenge amounts to is not mentioned. How a chimp can challenge a linguistic theory is still not clear to me.

Deacon's argument proceeds in three stages. He lays out what he considers to be the core of language (symbolic reference); works through the neurological ingredients that support his framework (the relative increase in the size of the prefrontal cortex); and presents his story of how language and the brain coevolved.

The central notion of what constitutes language for Deacon is symbolic reference. His conceptualization of this underlies the entire comparative and evolutionary story. Insofar as one is sceptical, the story becomes problematic. Drawing on the ideas of C. S. Peirce, Deacon argues that reference, the relation between words and the world, is iconic (based on the similarity between the object and the referring signifier), indexical (based on spatial or temporal contingencies) or symbolic. Humans alone are specialized for symbolic reference, and features such as knowledge of syntax are consequences of symbolic reference. Why are humans human? Not because they are hairless apes with language (the generative straw man) but because they have crossed a mystical "symbolic threshold", Deacon contends.

Much of this discussion is unsatisfying because Deacon is out of touch with research on language. For example, he constantly uses the expression "grammar and syntax" (both terms have technical definitions; Deacon defines neither); he seriously misinterprets the term "deep structure" (which has precise meaning in linguistics); and the view of language acquisition that he attributes to generative linguistics implies that research halted 30 years ago.

Deacon is at his best discussing neuroscience. His breadth of knowledge is impressive throughout; his description of the neural basis of vocalization is especially clear. It is central to his argumentation that the relative increase in the size of the prefrontal cortex in humans enlarged working memory and attentional capacity and made possible the better manipulation of symbolic representations.

Again, though, technical inaccuracies weaken the presentation. The brief discussion of neuroimaging, a field that is contributing considerably to our understanding of the neural basis of language, is out of date. In his discussion of Williams' syndrome, Deacon makes a lot out of preserved prefrontal cortex and cerebellum in the face of significant reductions in "posterior cortical systems". But the brain area typically associated with language processing (the planum temporale) turns out to be bigger, relative to overall brain size, in people with this condition.

Occasional stylistic excesses also do not help: "We are not just a species that uses symbols. The symbolic universe has ensnared us in an inescapable web. Like a 'mind virus,' the symbolic adaptation has infected us, and now, by virtue of the irrresistible urge it has instilled in us to turn everything we encounter and everyone we meet into symbols, we have become the means by which it unceremoniously propagates itself throughout the world".

When one makes big claims about how language works, one needs to show something about language: explicit, worked-out examples. A general discussion of what a theory might do does not suffice. Plainly, so expansive a book owes the reader more.

Who will like this book? Anyone who is already persuaded by the positions of Elman, Bates, Seidenberg and other anti-nativists. Those looking for a detailed explanation of language phenomena, within a framework that goes beyond speculation, will be disappointed. The 'bad guys' are still badder. David Poeppel is at the Biomagnetic Imaging Laboratory, University of California at San Francisco, San Francisco, California 94143-0628, USA. 